\title{
Corrigendum
}

\section{Corrigendum to "Recommendations for Diagnosis and Management of Osteoporosis in COPD Men"}

\author{
Elias E. Mazokopakis ${ }^{1}$ and Ioannis K. Starakis ${ }^{2}$ \\ ${ }^{1}$ Department of Internal Medicine, Naval Hospital of Crete, Chania, 73200 Crete, Greece \\ ${ }^{2}$ Department of Internal Medicine, Patras University Hospital, 26500 Rion-Patras, Greece \\ Correspondence should be addressed to Elias E. Mazokopakis; emazokopakis@yahoo.gr
}

Received 20 April 2017; Accepted 7 May 2017; Published 2 July 2017

Copyright (C) 2017 Elias E. Mazokopakis and Ioannis K. Starakis. This is an open access article distributed under the Creative Commons Attribution License, which permits unrestricted use, distribution, and reproduction in any medium, provided the original work is properly cited.

In the article titled "Recommendations for Diagnosis and Management of Osteoporosis in COPD Men" [1], there was an error regarding the FRAX ${ }^{\circledR}$ tool, which should be clarified as follows.

The article notes: "For example, the Garvan fracture risk calculator and the WHO fracture risk assessment tool (FRAX) are useful supplements to BMD assessments, as they help physicians to decide which patients might require prolonged treatment to reduce the risk of future fractures [24, 25]"; "The updated National Osteoporosis Foundation (NOF) guide based upon the WHO fracture prediction algorithm (FRAX), in conjunction with an updated US-specific economic analysis, provides also treatment recommendations for men with osteopenia on BMD." However, the World Health Organization (WHO) did not develop, test, or endorse the FRAX tool or its recommendations [2]. The metabolic bone disease unit at the University of Sheffield that developed FRAX was a WHO Collaborating Centre from 1991 to 2010, but treatment guidelines must undergo a formal process before they can be endorsed by the WHO.

\section{References}

[1] E. E. Mazokopakis and I. K. Starakis, "Recommendations for diagnosis and management of osteoporosis in COPD men," ISRN Rheumatology, vol. 2011, Article ID 901416, 8 pages, 2011.

[2] N. Ford, S. L. Norris, and S. R. Hill, “Clarifying WHO’s position on the FRAX ${ }^{\circledR}$ tool for fracture prediction," Bulletin of the World Health Organization, vol. 94, Article ID 862, 2016. 


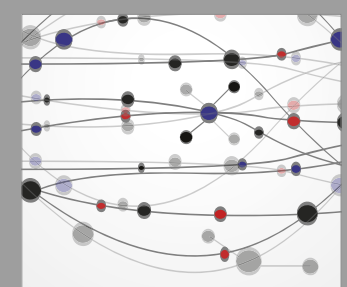

The Scientific World Journal
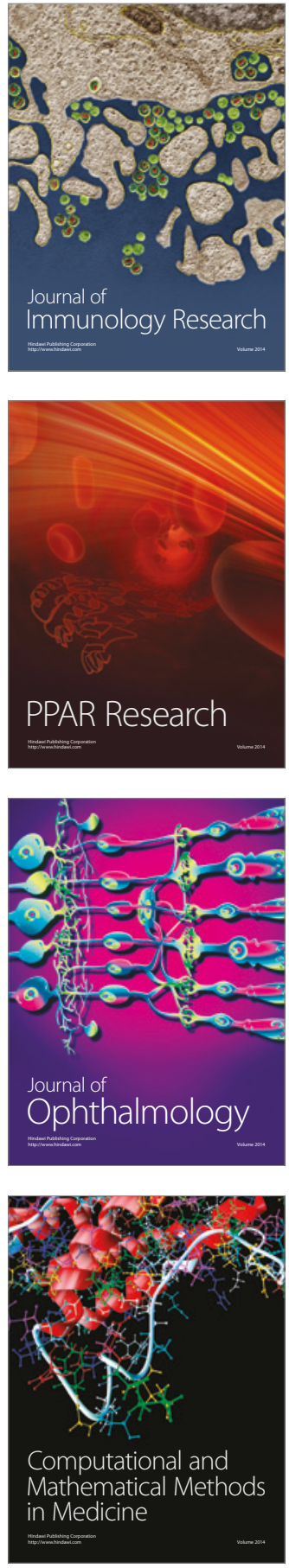

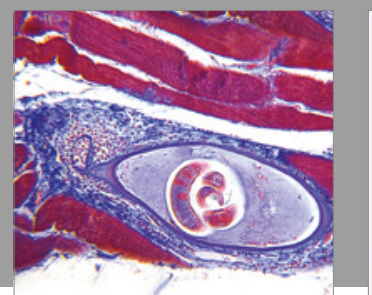

Gastroenterology Research and Practice
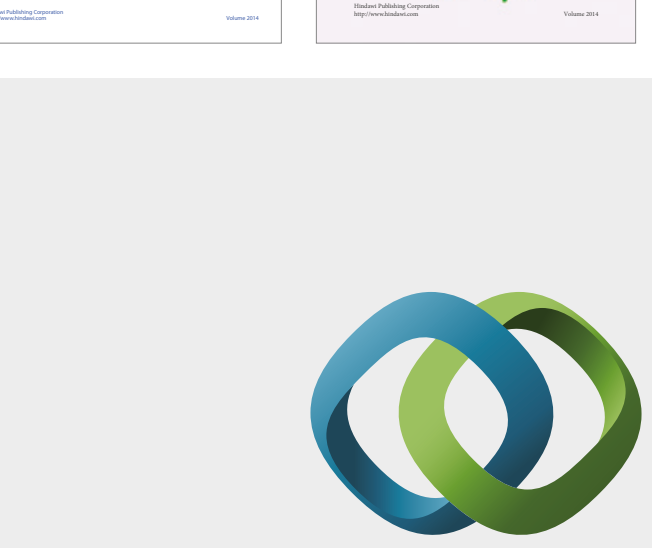

\section{Hindawi}

Submit your manuscripts at

https://www.hindawi.com
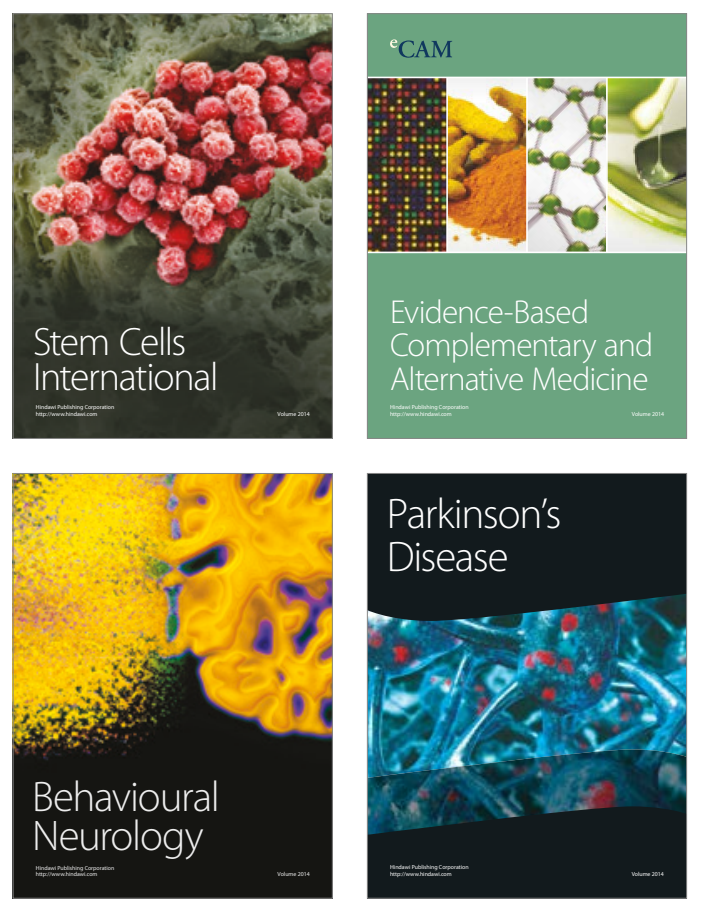
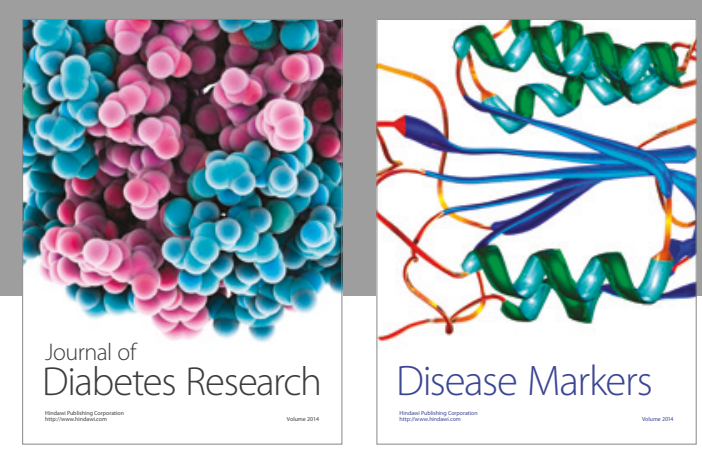

Disease Markers
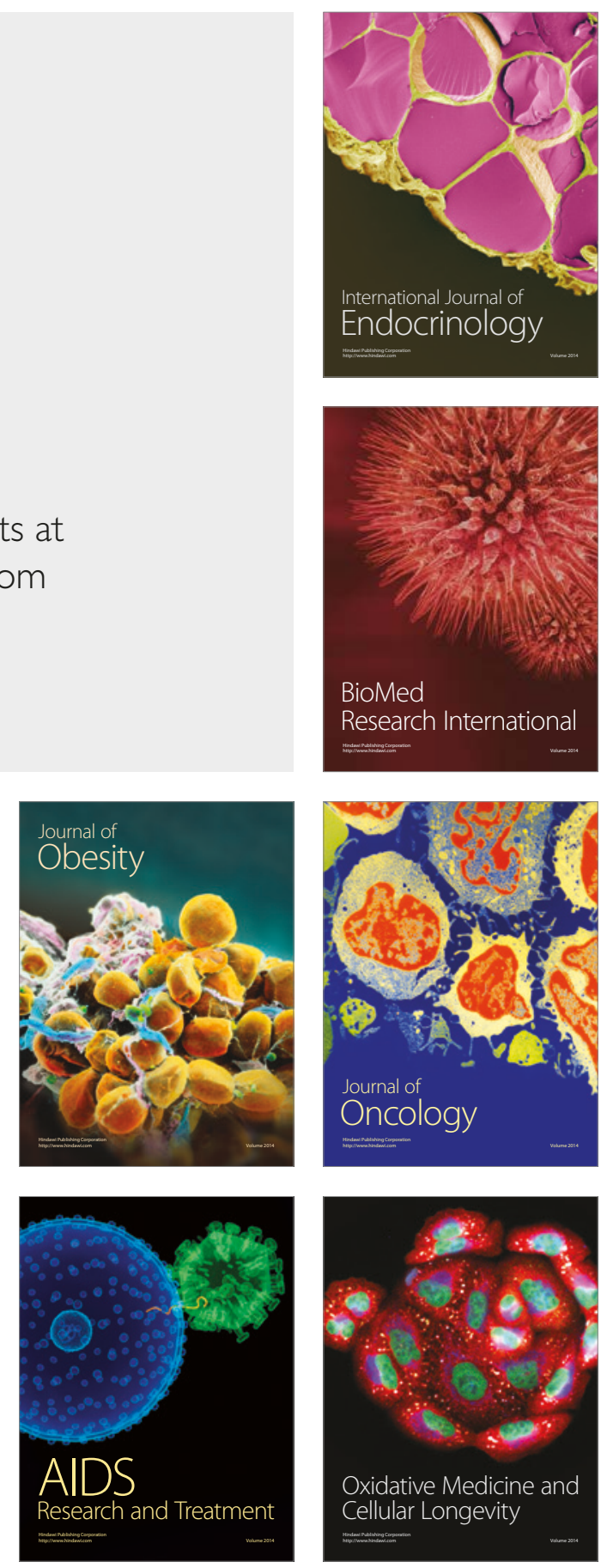